\title{
The Threat of Bioterrorism
}

Senator Bob Graham, D-FL; Senator Jim Talent, R-MO

$\mathrm{N}$ ext month, the Bipartisan WMD Terrorism Research Center (WMD Center) will release a report card on America's preparedness to respond to an act of bioterrorism. This will be the first strategic, end-to-end assessment of US bioresponse capabilities-from initial detection through diagnosis, communications, development and dispensing of medical countermeasures, medical management, and environmental cleanup.

The WMD Center is a not-for-profit research and educational organization that we founded, along with Col Randy Larsen, US Air Force (retired), at the conclusion of the Commission on the Prevention of Weapons of Mass Destruction Proliferation and Terrorism (WMD Commission) in 2010. Congress chartered the WMD Commission early in 2008 to assess the risk of WMD terrorism and to recommend steps to prevent a successful WMD attack on the United States. Through the WMD Center, we continue our bipartisan commitment to that goal.

\section{WORLD AT RISK}

During its tenure, the WMD Commission interviewed hundreds of experts and reviewed thousands of pages of research and testimony. It quickly became clear to every commissioner that the United States was facing a serious threat from biological terrorism. We learned that the lethality of a sophisticated biological weapon could rival the lethality of a Hiroshimasized bomb, and that the development and delivery of such a bioweapon would require far less money and technical expertise than a nuclear weapon.

In fact, if the Federal Bureau of Investigation (FBI) is correct about the anthrax letters of 2001, then a single individual with no training or experience in weaponizing pathogens and no equipment that was not readily available for purchase on the Internet was capable of producing high-quality, dry-powder anthrax. The only difference between producing enough material for several envelopes and enough material to attack a city is just a matter of a few months' production work, rather than the few hours as noted in the FBI report.

The effective dissemination of a large quantity of a weaponized pathogen such as anthrax would not require nationstate technologies. The ease of large-scale aerosol release was recently demonstrated by the Department of Defense. To test the biosensors at the Pentagon, a simulant was released upwind of the Pentagon. The device used to disperse the simulant was a $\$ 49.95$ leaf blower purchased at a local hardware store.

For these and many other reasons, our commission report World at Risk stated that terrorists are more likely to obtain and use a biological weapon than a nuclear weapon. In late fall 2008, we concluded that "unless the world community acts decisively and with great urgency, it is more likely than not that a weapon of mass destruction will be used in a terrorist attack somewhere in the world by the end of 2013." On December 2, 2008, VADM John Michael McConnell, the Director of National Intelligence, publicly agreed with this assessment in a speech at Harvard University.

In an unprecedented act, Congress extended the authorization of the WMD Commission and assigned it a new task: to communicate its assessment, explain the evidence behind it, and to work with Congress and the Obama administration to enact the WMD Commission's recommendations. In other words, we were charged with encouraging Congress and the administration to take decisive action to prevent an act of mass lethality from taking place on American soil, and should such an attack occur, to limit its consequences.

In 2009, the WMD Commission worked closely with Congress and the Administration to focus on the threat of bioterrorism. As our second year of work drew to a close, we released a report card that assessed progress on a wide range of WMD issues; however, the grade that garnered the most attention in the January 2010 report was the failing grade given for America's preparedness to respond to a biological attack. Aside from raising the obvious national security concerns, this assessment was also a poor reflection on government, given that the United States had spent more than $\$ 60$ billion on biodefense since the terrorist attacks of September 11, 2001. These issues made bioresponse a logical focus for our newly formed WMD Center.

We believe that there are many reasons for this lack of progress, but one primary reason is that no one is in charge of coordinating the US biodefense enterprise. At the federal level, there are more than two dozen presidentially appointed, Senateconfirmed individuals with some responsibility for biodefense, and yet not one has this as a full-time job.

\section{WMD CENTER REPORT CARD}

This is but one issue examined in the WMD Center's forthcoming report. Lynne Kidder, the president of the WMD Center, has led a highly qualified team of experts in this effort. The project's board of advisors designed the metrics used to assess various components of the bioresponse enterprise. Those advisors included a former Deputy Commissioner of the Food and Drug Administration, a former Chief Counsel at the Centers for Disease Control and Prevention, a former Special Assistant to the President for Biodefense (in the Clinton and G.W. Bush administrations), the Director of Disaster Medicine at the American Medical 
Association, and the Director of RAND Health. (A complete list of advisors is available at www.wmdcenter.org.)

After the project's board of advisors determined metrics, a separate, independent team of subject matter experts performed an evaluation and analysis of capabilities in each category. To ensure rigorous review and diverse perspectives, this team included experienced practitioners and thought leaders from academia and leading think tanks plus former senior government officials and subject matter experts from private sector organizations that specialize in biodefense. These experts provided their analyses and insights to the WMD Center Board of Directors, which is responsible for the final determination of grades, recommendations, and report content.

\section{LACK OF PROGRESS}

In light of the failing grade provided by the WMD Commission, the commitment that was pledged by President Obama in his State of the Union Address, and repeated recommendations by various groups attempting to correct these deficiencies, one may ask the question, "Why are we not making more progress?"

There are several reasons. First, successful biodefense requires an incredibly complex enterprise of federal, state, and local governments and private sector actors, both commercial and notfor-profit. The US government is attempting to manage this complex enterprise without a designated leader or a unified management structure.

Second, the science involved is extraordinarily challenging. Frankly, it makes the moon shot in the 1960 s seem simple. The laws of physics are well known and predictable, but biology is more complex. To use the scientific terminology from an advisor at the WMD Commission, "Biology is squishy."

Third, many senior government officials do not understand the nature of the 21st-century threat of bioterrorism and therefore do not consider biodefense to be a high national-security priority. Many of the same individuals may not recognize the collateral benefits of investing in biodefense. Improvements in the rapid diagnosis of disease, the capability to quickly produce safe and effective vaccines and therapeutics, and surge capacity in our medical care systems will benefit us all, whether we experience a large-scale bioterrorist attack or a naturally occurring disease pandemic. These no-regret initiatives will be a great legacy for our children and grandchildren, and will also help keep America at the leading edge of the biotechnology revolution.

In 2009, the United States responded to the threat of the H1N1 influenza pandemic by using 60-year-old technology to produce a vaccine. Mother Nature gave us five months' advance warning. Bioterrorists are likely to give us none. That is why the WMD Commission produced a short video calling for major improvements in how America produces important medical countermeasures (www.fastervaccines.org). We would not want our armed forces to be dependent upon 60-year-old technologies, so why should we accept obsolete technologies to protect our families?

\section{ROADMAP FOR PROGRESS}

There is good news in that America has the ability to remove bioterrorism from the category of a WMD. It will always be a weapon, but a nation that is properly prepared can respond in a manner that will significantly reduce the casualties. We call it "moving the decimal point to the left."

Casualties would not be counted in hundreds of thousands, tens of thousands, or even thousands. Major improvements in all seven areas being assessed in the WMD Center report card could prevent a large-scale act of bioterrorism from becoming an event that would change the course of history.

To achieve this goal, we must first correct three deficiencies: First, America's biodefense enterprise must have a strategic leader who has the appropriate authority, responsibility, and accountability. Second, although the science and technology of biodefense are formidable, success is within our reach if Congress and the Administration acknowledge biodefense as a national security priority. Unfortunately, that is not the case today. Both the WMD Commission and the WMD Center have argued repeatedly that funding organizations like the Biomedical Advanced Research and Development Authority (BARDA) at 10\% of actual requirements will not place America on the road to success. Third, those of us who understand the seriousness of the growing threat of bioterrorism must redouble our efforts to educate America's leaders. Leaders in both the public and private sectors must understand the realities of the threat, the actions required to dramatically reduce that threat, and the myriad benefits that will be realized from the reduction.

The question is the same as when the WMD Commission issued its first report in December 2008: Will our leaders take bold actions commensurate with the seriousness of this threat?

Author Affiliations: Former Senators Bob Graham and Jim Talent served as the chair and vice chair, respectively, of the Congressional Commission on the Prevention of Weapons of Mass Destruction Proliferation and Terrorism and currently serve as the chair and vice chair of the WMD Center, a 501 (c)(3) not-for-profit research and education organization.

Correspondence: Address correspondence and reprint requests to the journal.

Received for publication July 1, 2011; accepted July 5, 2011.

Author Disclosures: The authors report no conflicts of interest. 